\title{
Aplicação da hipótese de fragilidade financeira na economia brasileira: Uma análise do problema fiscal do governo Dilma Rousseff
}

\author{
Eduardo Prado SouzaI, Marcelo Arend ${ }^{\mathrm{II}}$
}

\begin{abstract}
RESUMO
O presente trabalho tem como principal objetivo aplicar a hipótese de fragilidade financeira no setor público brasileiro para conseguir analisar e buscar possíveis justificativas para o problema fiscal do governo de Dilma Rousseff, sendo dessa forma necessária uma análise dos governos anteriores, bem como trazer o arcabouço pós keynesiano através do indicador de fragilidade financeira desenvolvido por Fabio Terra e Ferrari Filho para fundamentação desta. O que se concluiu é que as variáveis fiscais corroboram o problema fiscal, e mesmo que o indicador de fragilidade financeira tenha resultado em um valor especulativo, é denotado uma situação relativamente frágil para o setor público, que é basicamente justificado pelas políticas adotadas durante o governo de Dilma Rousseff, mas que também são justificados pelas atuações de governo anteriores.
\end{abstract}

Palavras-chave: Hipótese de fragilidade financeira; Problema fiscal; Dilma Rousseff

\section{ABSTRACT}

The main objective of this research is to apply the financial fragility hypothesis in the Brazilian public sector in order to analyze and search for explanation for Dilma Rousseff's Government fiscal problems, to reach at conclusions is necessary to analyse the provious governments and bring the post keynesian theory through the financial fragility indicador, which was done Fabio Terra and Ferrari Filho . What has been concluded is that fiscal variables corroborate the fiscal problem, and even though the indicator of financial fragility has resulted in a speculative value, it is denoted an extremely fragile situation for the public sector, which is basically justified by the policies adopted during Rousseff's government, but which are also justified by previous government actions.

Keywords: Financial fragility hypothesis; Fiscal problem; Dilma Rousseff

\footnotetext{
I Mestrando em Desenvolvimento Econômico pela Universidade Federal do Paraná - <eduprado1995@gmail.com

IIPós-Doc (2015/1016, Universidad Autónoma de Madrid) - marcelo.arend@ufsc.br
} 


\section{INTRODUÇÃO}

O papel do Estado tem distintas interpretações dentro das várias correntes do pensamento econômico, destacando principalmente as premissas sobre o seu tamanho ou sua interferência na economia, e até se sua existência é realmente necessária. Apesar de ter muitas interpretações, o presente trabalho focará na visão Keynesiana e Pós-Keynesiana, por apresentarem uma análise robusta sobre seu papel na economia. Esta visão coloca o papel do Estado como tendo importância para o funcionamento da economia, dado que este possui o papel de estabilizador e de reversão cíclica (MINSKY, 2013, p.336-350). É nessa visão de agente estabilizador, que se dará a importância necessária que o governo tem, dado que para conseguir impor seu papel na economia, este precisará ter uma estrutura de governo estável e extremamente solvente, capaz de lidar com as estabilidades inerentes ao sistema capitalista. Consoante a essa visão que entra o trabalho de Hyman Minsky ao expor a Hipótese de Fragilidade Financeira e inerente a ela, a taxonomia adotada para as firmas do sistema econômico, na qual este avalia o funcionamento de uma economia inerentemente instável e como os agentes econômicos interagem nela.

Apesar de Minsky ter elaborado sua Hipótese de Fragilidade Financeira para as firmas, nada contraria a ideia de usar esta em outro agente econômico, nesse caso o próprio governo. O arcabouço teórico desenvolvido por Minsky foi utilizado já em muitos trabalhos de diferentes formas, mas em específico para o governo brasileiro, o trabalho realizado por Terra e Ferrari Filho (2011) elaborou uma análise robusta para o primeiro e segundo governo de Luiz Inácio Lula da Silva, para o qual construiu um indicador de fragilidade financeira e aplicou a estrutura governamental deste presidente.

O governo Dilma Rousseff passou por muitos problemas dentro de seus dois mandatos, mas um dos maiores foi a crise" fiscal que ocorreu em seu governo evidenciada pelo repique da dívida e déficit primário. Nesse tocante o presente trabalho buscará aplicar a hipótese de fragilidade financeira de Hyman Minsky na economia brasileira, em especifico ao governo Dilma Rousseff, a fim de explicar e evidenciar possíveis justificativas ao problema fiscal que se instaurou em seu governo e se prolongou no governo seguinte

O presente trabalho está organizado em cinco capítulos, sendo eles essa breve introdução, seguido do segundo capítulo que trará um breve referencial teórico keynesiano e pós keynesiano, evidenciando a hipótese de fragilidade financeira de Hyman Minsky. O terceiro capítulo busca trazer um arcabouço histórico da economia brasileira contemporânea, em específico uma descrição histórica sobre o período que vai desde o pós plano real até o governo de Dilma Rousseff. O quarto capítulo busca aplicar a hipótese de fragilidade financeira de Hyman Minsky na economia brasileira, a fim de tentar elencar as justificativas para o problema fiscal conjuntural. O quinto e último capítulo será as considerações finais. 


\section{A VISÃo Pós KEYNESIANA e A HIPÓtese de FRAGILIDADE FINANCEIRA}

A teoria pós keynesiana é a corrente que mais segue os preceitos da teoria keynesiana, trazendo os principais postulados da corrente mas avançando cada vez mais para entender as atuais economias e como elas funcionam. Dentro dos preceitos que a corrente segue vale ressaltar alguns princípios que contrapõe a visão ortodoxa clássica e que caracterizam bem a corrente pós keynesiana.

Davidson (2003) elenca três princípios keynesianos que contrapõe aos axiomas da ortodoxia clássica, sendo eles o princípio da não-neutralidade da moeda, princípio da não ergodicidade e princípio da incerteza absoluta. 0 primeiro afirma que a moeda não é neutra, e possui impacto sim sobre o lado real da economia, muito devido a possuir mais papeis além de meios de troca, possuindo papel de precaução e especulação. Essa visão da moeda não ser neutra, transforma a economia além de ser capitalista, em uma economia monetária, dado que de acordo com Carvalho (1989, p.189) nesse tipo de economia a moeda deixa de ser mera conveniência temporária, afetando sim as decisões dos agentes tanto no presente quanto no futuro.

O segundo princípio afirma que o passado e o presente não são bons parâmetros para a tomadas de decisões, dado que muitas variáveis são afetadas por expectativas futuras. O terceiro é uma junção dos dois primeiros e afirma que a economia é um meio de incerteza absoluta, aonde a sociedade buscar meios para se adaptar a ela.

A visão keynesiana e pós keynesiana é baseada na teoria da demanda efetiva, que contrapõe o postulado da Lei de Say, definido por Possas (1999, p.19) como a "determinação unilateral das receitas (renda) pelos gastos; em outras palavras, na constatação de que nas transações mercantis a única decisão autônoma é a de gastar", ou seja, não é a oferta que gera as condições para a demanda, e sim o contrário.

O estado por essas visões possui papeis bastante importante para economia, dado que a economia não é autocorretiva, o estado possui o papel de reversão cíclica, expandindo a demanda em períodos de recessão, a fim de retomar a confiança dos agentes econômicos (CARVALHO, 1999, p. 268-269). O estado também ganha o papel de agente estabilizador nessa corrente, garantindo a confiança dos agentes e propiciando um ambiente propicio para a realização do investimento. Minsky (2013) já elenca os dois principais agentes da economia, sendo eles o Big Government (tendo como papel de intervir em situações críticas, tendo superávits e controle da inflação em momentos de boom, déficit e alguma inflação em momentos de depressão) e o Big Bank Center (com o papel de deixar um ambiente líquido aos agentes e limitar, quando necessário, os comportamentos excessivos).

A visão keynesiana é baseada numa visão de mundo moderno, de uma economia monetária e financeira na qual os agentes tomam suas decisões de gastos baseado no futuro, sob incertezas, e que presume ciclos econômicos e equilíbrios subótimos. Além disso, a teoria afirma que o sistema capitalista é instável por natureza, e que agentes econômicos como o estado possuem papel de grande importância para o funcionamento da economia. 
A teoria pós keynesiana, é a continuação da teoria keynesiana que mais segue os preceitos de Keynes, visando é claro uma modernização da sua teoria, corrigindo erros, quebrando limitações, sem fugir dos princípios básicos do modelo. Dentre os autores e trabalhos pós keynesianos com maior destaque, se encontra Hyman Minsky e sua hipótese de fragilidade financeira, baseada no processo de financeirização das economias, além do processo inerentemente endógeno de instabilidade do sistema capitalista.

Minsky (2013) afirma que as economias modernas se encontram no que ele chamou de paradigma de Wall Street, no qual é caracterizada como uma economia mercantil, monetária e financeira, aonde por meio da financeirização, há uma relação muito forte entre o setor produtivo e o setor financeiro na economia, e que as crises são formadas no setor financeiro primeiro e afetam posteriormente o lado real da economia.

Como as instabilidades da economia são formadas endogenamente, Minsky (2013) faz uma análise das estruturas de financiamentos dos agentes econômicos, construindo uma taxonomia dos fluxos de caixas dessas estruturas, elencando três tipos de agentes, sendo eles Hedge, Especulativo e Ponzi. Kindleberger e Aliber (2013, p.34-35) define essas estruturas como:

Uma empresa estará no grupo de finanças de hedge se sua receita operacional prevista for mais do que suficiente para pagar os juros e a redução prevista das suas receitas. Fará parte do grupo das finanças especulativas se sua receita operacional prevista for suficiente para pagar os juros das suas dívidas. Entretanto, ela deve usar dinheiro de novos empréstimos para pagar todo o valor (ou parte dele) devido em empréstimos. Uma empresa se encaixará no grupo Ponzi se sua receita operacional prevista for menor do que aquela necessária para pagar todos os juros das suas dívidas nas datas previstas; nesse caso, ela deve aumentar sua dívida ou vender alguns ativos para obter dinheiro para esses pagamentos.

Vale ressaltar com base na definição de Kindleberger e Aliber (2013), que empresas do tipo Hedge são extremamente solventes e líquidas, e assim sendo possuem uma margem de segurança grande. Empresas Especulativas são solventes, mas possuem períodos de iliquidez, denotando assim uma margem de segurança menor. Já empresas Ponzi, são tanto ilíquidas quanto insolventes, e sendo assim praticamente não possuem margem de segurança.

É baseado nessa taxonomia, que Minsky (2013) afirma que a própria prosperidade propicia o ambiente favorável a instabilidade econômica, dado que em períodos de prosperidade econômica, os agentes se sentem mais favoráveis a se arriscar, e assim se endividando cada vez mais. Dessa forma na primeira fase a tendência é que haja mais agentes Hedge, do Especulativo e Ponzi respectivamente, já no prolongamento do período de prosperidade, a tendência é que haja mais Especulativo que Hedge, e Ponzi respectivamente. No caso extremo, haverá mais agentes Ponzi que Especulativo e Hedge, denotando no que Minsky (2013) afirma ser o estado de fragilidade financeira na economia. Tal conclusão pode ser simplificada no trecho do autor a seguir: 
A combinação de situação Hedge, Especulativo e Ponzi é um dos grandes determinantes da instabilidade dos sistemas econômicos. A presença de um grande número de empresas em situação Ponzi ou especulativa é uma condição necessária para a instabilidade financeira. (MINSKY, 2013, p. 234).

Estando nessa situação de fragilidade financeira, qualquer alteração da taxa de juros pode trazer muitos problemas para essas empresas. Supondo um aumento da taxa de juros, as empresas teriam que buscar meios alternativos para quitação de suas dívidas, e recorreriam ao mercado financeiro, na venda de títulos e ações. Dado um aumento da oferta de títulos, com a demanda intacta, gerará uma deflação dos títulos, levando a um novo aumento da taxa de juros. Tal cenário corrobora a crise no sistema financeiro, que impactará os investimentos negativamente, afetando assim o lado real da economia. É dessa forma que Minsky (2013) demonstra que as reversões cíclicas podem ter componentes endógenos ao sistema capitalista, e que a própria "estabilidade" econômica gera a instabilidade na economia.

\section{ANÁLISE HISTÓRICA BRASILEIRA: DO PLANO REAL A DILMA}

O plano real pode se colocar como um marco histórico de rompimento do processo de hiperinflação, crise política e econômica, ocorrido após a crise brasileira dos anos oitenta, ocasionado pelo segundo choque do petróleo, o repique dos juros internacionais e pela situação fragilizada em que a economia brasileira se encontrava no final dos anos setenta. Este se dividiu em três partes, sendo um ajuste fiscal prévio, com intuito de reorganização das contas públicas e estabilização do problema fiscal, a indexação completa da economia através da moeda fictícia conhecida pela URV, para solução da inflação inercial, sendo para isso necessário a colocação de uma nova moeda no mercado, conhecida como real, e as ancoras monetárias e cambial, sendo a primeira para controle da inflação de demanda e a segunda para controle do câmbio através de câmbio fixo e posteriormente de bandas cambiais (GREMAUD;VASCONCELOS JR, 2002, p.445 - 451)

O decorrer do pós plano real e o fim da inflação inercial no comando do presidente Fernando Henrique Cardoso foi bastante conturbado, dado que o enfoque do problema se tornou outro, agora relacionado com as oscilações da taxa de crescimento do produto interno bruto e ao mesmo tempo a elevação tanto do desemprego quanto da dívida total. Esses efeitos negativos das variáveis econômicas estão bastante ligados as crises externas ocorridas entre 1995 á 1998, sendo elas a crise mexicana, a crise asiática e a crise Russa, todas relacionadas a especulação da moeda local, que leva a desvalorização cambial e repique inflacionário. O Brasil manteve a taxa de câmbio fixa nas duas primeiras crises, queimando reservas e elevando sua dívida, até que na crise russa se tornou insustentável e o Brasil volta a utilizar um câmbio mais flexível (GREMAUD;VASCONCELOS JR, 2002, p.450 - 469).

Em 1998, o FMI intervém na economia brasileira, lançando o programa de estabilidade fiscal, que tinha como principal meta construir um ajuste fiscal que levasse a economia brasileira mais próxima aos padrões globais, 
colocando a política fiscal como principal fator para a estabilidade das variáveis macroeconômicas (LOPREATO, 2014, p. 231). Baseado nesse programa e numa ideologia mais neoliberal, no final dos anos noventa, Fernando Henrique Cardoso lança o Tripé Macroeconômico, que serviria como guia para as políticas econômicas dali em diante. Esse tripé é dividido em metas de inflação, no qual limita os poderes do Bacen, estipulando metas de inflação a serem seguidas pelo país para manter a situação econômica, as taxas de câmbio flexível, devido a insustentabilidade de manter elas fixas anteriormente, e as metas de superávit primário, dando maior credibilidade ao setor fiscal brasileiro (GREMAUD; VASCONCELOS JR , 2002, p.475 - 485).

O governo de Lula inicia com uma série de fatores negativos, ligados as crises externas, baixo crescimento econômico, crise fiscal, uma grande incerteza ligada ao seu governo, mas ao mesmo tempo uma confiança bastante grande da população, muito devido ao seu discurso, que propunha uma mudança gradual em comparação ao governo anterior e ao mesmo tempo o processo de inclusão social (ERBER,2011, p.13-15).

Erber (2011) apresenta duas convenções que norteiam todos os dois mandatos do governo de Luiz Inácio Lula da Silva, intituladas de convenção institucionalista restrita e a neo - desenvolvimentista, que conviveram juntas durante todo o mandato do presidente, sendo que só no final uma delas prevalece sobre a outra. A primeira convenção caracterizada por Erber (2011) como institucionalismo restrito, é praticamente um legado deixado pelo governo anterior de $\mathrm{FHC}$, que já se encontra nos primeiros anos do governo Lula, quando este aplica uma série de medida contracionistas, baseada principalmente na manutenção do tripé macroeconômico. Seguindo essa linha então vale ressaltar que o governo Lula manteve as metas de inflação em quase todos os anos, exceto no primeiro, manteve as metas de superávit primário em todos os anos, com crescimento econômico acelerado e queda da proporção divida/PIB.

A segunda convenção esta ligada aos avanços sociais ocorridos no país, que podem ser exemplificado pela redução tanto da pobreza quanto da pobreza extrema, que estão ligadas principalmente as políticas de transferência de renda, a redução do índice de Gini, evidenciando uma redução leve da desigualdade no país, a elevação do salário médio anual e ao mesmo tempo uma redução drástica do desemprego no país, muito relacionado com o avanço do setor de serviços no país (SINGER, 2010).

Cabe notar então que ambas as convenções do governo Lula conviveram juntas, até o período da crise econômica mundial de 2008, quando a convenção institucionalista restrita se torna hegemônica na construção de políticas anticíclicas, com expansão dos gastos, exemplificado por exemplo pelo programa Minha Casa Minha Vida, e contenção do processo de impacto da crise, sem deixar de continuar com as perspectivas sociais. $O$ resultado pós crise foi positivo, com a retomada do crescimento econômico e o final do mandato Lula acaba sendo positivo no geral (ERBER, 2011, p.3237).

Depois das várias mudanças ocorridas durante o mandato de Luiz Inácio Lula da Silva, através da volta do crescimento econômico, bem como melhora dos indicativos macroeconômicos e sociais, o governo Dilma Rousseff 
entra em vigor em 2011 sem discurso de mudança, elencando apenas o grande desempenho do governo anterior, e priorizando o processo de continuidade desse processo de melhorias (LOPREATO, 2014, p. 240). Além de suceder um governo bastante positivo, o governo Dilma inicia com os desdobramentos da crise econômica de 2008, sendo para isso necessário uma serie de políticas anticíclicas para o combate a esta.

Singer (2015) contrapõe melhor essa análise dos primeiros anos do governo de Dilma Rousseff, apresentando um termo, colocado pelo próprio ministro da fazenda da época, Guido Mantega, intitulado de "Nova Matriz Econômica", que é o termo colocado para as políticas anticíclicas adotadas durante o primeiro mandato do governo Dilma Rousseff. Essa nova matriz possui uma série de políticas que combinam basicamente os avanços a volta do crescimento econômico, mas ao mesmo tempo políticas mais nacionalistas e protecionistas de incentivo a industria interna. Nos pilares dessa matriz se encontra a redução dos juros e a desvalorização do real, sendo a primeira ocorrida até o segundo semestre de 2012, e a segunda se manteve até o final do governo Dilma.

Uma das principais políticas feitas durante o governo de Dilma Rousseff foi a criação do Plano Brasil Maior, organizado de maneira a obter certo protecionismo para sustentar um crescimento econômico a base do nível de investimento, bem como aumentar a competitividade interna da indústria, frente ao comércio externo, através da atuação do BNDES, utilizando o ferramental de subsídios a determinadas empresas (SINGER, 2015). Em resumo o governo Dilma teve um aumento significativo da taxa de desemprego, elevação da inflação, repique da dívida tanto total quanto do setor público e um crescimento muito fraco do nível de investimento no país que após 2013 começou a cair novamente.

Singer (2015, p. 54 - 64) coloca que a presidente Dilma Rousseff, diferentemente do presidente Lula, enfrentou inúmeros embates para a manutenção de um projeto mais nacionalista, principalmente ligados ao embate com o rentismo1 bancário (devido à queda da taxa de juros, aumento da competitividade e redução da lucratividade bancária), da burguesia industrial (que não aderiu aos incentivos de investimento, muito correlacionado ao processo de financeirização da economia moderna atual, bem como a limitação da entrada de capitais externos), da população brasileira como um todo (com o aumento da inflação, do desemprego, redução do produto interno), que resultou no fim do ensaio desenvolvimentista adotado pela presidente.

Cabe ressaltar que mesmo com o processo de reeleição em 2015 (processo esse bastante disputado), os problemas econômicos apenas se aprofundaram, e com os escândalos de corrupção, das pedaladas fiscais, e aprofundamento do presidencialismo de coalizão, levaram em agosto de 2016, ao fim do mandado de Dilma Rousseff da presidência do país, através do Impeachment. 


\section{APLICAÇÃO DA HIPÓTESE DE FRAGILIDADE FINANCEIRA}

\subsection{O INDICADOR DE FRAGILIDADE FINANCEIRA}

Poder-se-á notar que o setor público possui uma abrangência muito grande sobre praticamente todas as esferas do governo, colocando assim a análise sobre os fluxos de receitas e despesas muito mais robustos, principalmente no tocante ao problema fiscal brasileiro. Para isso será usado a metodologia apresentada por Terra e Ferrari Filho (2011) para a construção de um indicador de fragilidade financeira para o setor público brasileiro, trazendo a abordagem da hipótese de fragilidade financeira apresentada por Minsky (2013) para um setor diferente da sua teoria, que é abordada para os agentes e firmas econômicas, que nesse caso será trazida para o setor público.

Como a maioria dos modelos econômicos, o indicador é inicialmente formulado partindo de uma situação de equilíbrio, no qual as receitas menos os gastos correntes são iguais aos gastos financeiros. Cabe ressaltar que Terra e Ferrari Filho (2011) explicitam como receitas totais a soma da arrecadação tributária, da receita de capital e por outras fontes, e como gastos financeiros a soma dos gastos com amortizações e juros e encargos da dívida. Essa situação de equilíbrio pode ser exemplificada pela equação 1 :

$$
(\mathrm{T}+\mathrm{Rk}+\mathrm{Rof})-\mathrm{G}=\mathrm{Ga}+\mathrm{Gi}
$$

Denominasse com $T$ as receitas tributárias, com $R k$ as receitas advindas de capital e Rof as receitas de outras fontes, com $G$ as despesas correntes (essas em questão serão determinadas pela subtração dos juros e encargos das despesas correntes, mais a soma de investimentos e inversões financeiras, gerando as despesas não financeiras do setor público), Ga os gastos com amortização e Gi os gastos com juros e encargos da dívida, que junto denominam os gastos financeiros do setor público. Partindo dessa situação de equilíbrio, dividir-se-á ambos os lados pelos gastos financeiros e ter-se-á a seguinte expressão:

$$
\frac{(\mathrm{T}+\mathrm{Rk}+\mathrm{Rof})-\mathrm{G}}{\mathrm{Ga}+\mathrm{Gi}}=1
$$

A partir desse resultado, Terra e Ferrari Filho (2011) consegue descrever o setor público brasileiro através da taxonomia apresentada por Minsky (2013), apresentando os três tipos de situação que o setor público pode assumir, denominando assim a sua situação de fragilidade financeira. 0 setor público será dito Hedge então quando apresentar a seguinte expressão:

$$
\frac{(\mathrm{T}+\mathrm{Rk}+\mathrm{Rof})-\mathrm{G}}{\mathrm{Ga}+\mathrm{Gi}}>1
$$


Ou seja, serão Hedge, quando os valores das receitas menos os gastos correntes forem superiores aos gastos financeiros. Nessa situação, Terra e Ferrari Filho (2011, p. 502), apontam em consonância ao trabalho de Minsky (2013) que o setor público aqui se torna um agente líquido e extremamente solvente, não necessitando se refinanciar para pagar seus gastos. Nessa situação então o setor público é um agente extremamente seguro, e consegue lidar com os choques existentes na economia. O setor público será dito Especulativo quando apresentar a seguinte expressão:

$$
0<\frac{(T+R k+R o f)-G}{G a+G i}<1
$$

Nesse caso, o setor público será Especulativo, quando as receitas totais forem suficientes apenas para cobrir os gastos correntes, e sendo assim apresentarão valores entre 0 e 1 . Consoante a teoria de Minsky (2013), Terra e Ferrari Filho (2011) mostram que o setor público nessa situação só consegue superávits frente aos gastos correntes, tornando-o em algumas situações ilíquidos, tirando sua solvência, colocando a necessidade de buscar financiamentos para a rolagem da dívida. A última situação, considerada extrema por Minsky (2013), pode ser exemplificada na fórmula abaixo:

$$
\frac{(T+R k+R o f)-G}{G a+G i}<0
$$

Nessa situação temos o agente Ponzi, intitulado por alguns autores como agente devedor, que como pode ser visto pela fórmula cinco, as receitas totais não conseguem cobrir nem seus gastos correntes e nem seus gastos financeiros, se tornando assim um agente extremamente instável no tocante a fragilidade, sendo um agente insolvente e ilíquido, necessitando sempre de financiamento para pode cobrir todas as suas despesas (TERRA; FERRARI FILHO, 2011, p. 503).

Para a construção do indicador de fragilidade financeira do setor público foram usados os valores das contas consolidadas do setor público apresentadas nos balanços do setor público nacional, divulgados pelo site do tesouro nacional brasileiro. A figura 11 evidencia então o resultado do indicador de fragilidade financeira para os anos de 2000 até 2016, sendo gerado a partir da formula pré-estipulada anteriormente. Nota-se pela Figura 11 que 0 indicador fica entre 0 e 1 durante todo o período analisado, afirmando então que o setor público brasileiro se figurou em uma situação especulativa durante todo o período, mesmo que em alguns períodos tenha se notado que o valor ficou bem próximo de 1 , o que configuraria uma situação Hedge, ou bem próximos de 0 o que configuraria uma situação Ponzi. Dado que se obteve uma situação especulativa, poder-se-á concluir que para todos os anos do governo Lula e do governo de Dilma Rousseff, as receitas totais da 
consolidação das contas públicas foram suficientes apenas para pagar o montante referente aos gastos não financeiros, sendo incapaz de suprir os gastos financeiros, gerando certo grau de insolvência, e necessidade de buscar financiamento. O indicador apresentou seus maiores valores em 2002 (período de grande turbulência econômica, com transição ao governo Lula), em 2004 (sendo o período de adaptação ao governo Lula com as políticas anticíclicas já adotadas, e com o processo de reabilitação do crescimento econômico), e em 2011 (período de inicio do governo de Dilma Rousseff, com a adoção de políticas anticíclicas a crise econômica mundial de 2008). Já o indicador atinge seus menores valores em 2013, 2014 e 2016, já no governo de Dilma Rousseff, com os efeitos da Nova Matriz Econômica consolidadas, sendo a volta do crescimento da taxa de juros, bem como uma apreciação do real, sem contar com as eleições conturbadoras daquele ano. Apesar da tendência de queda, o que se nota é uma recuperação do indicador pós 2014, com retomada do crescimento desse valor, mas com queda novamente em 2016. Por fim cabe ressaltar que foram tiradas da construção do indicador as operações de crédito das receitas de capital, por configurarem dívida nova, e nos últimos anos os valores de amortização foram superestimados, devido à junção metodológica nos últimos boletins de algumas variáveis nela.

Figura 1 - Índice de fragilidade financeira de 2000 - 2016.

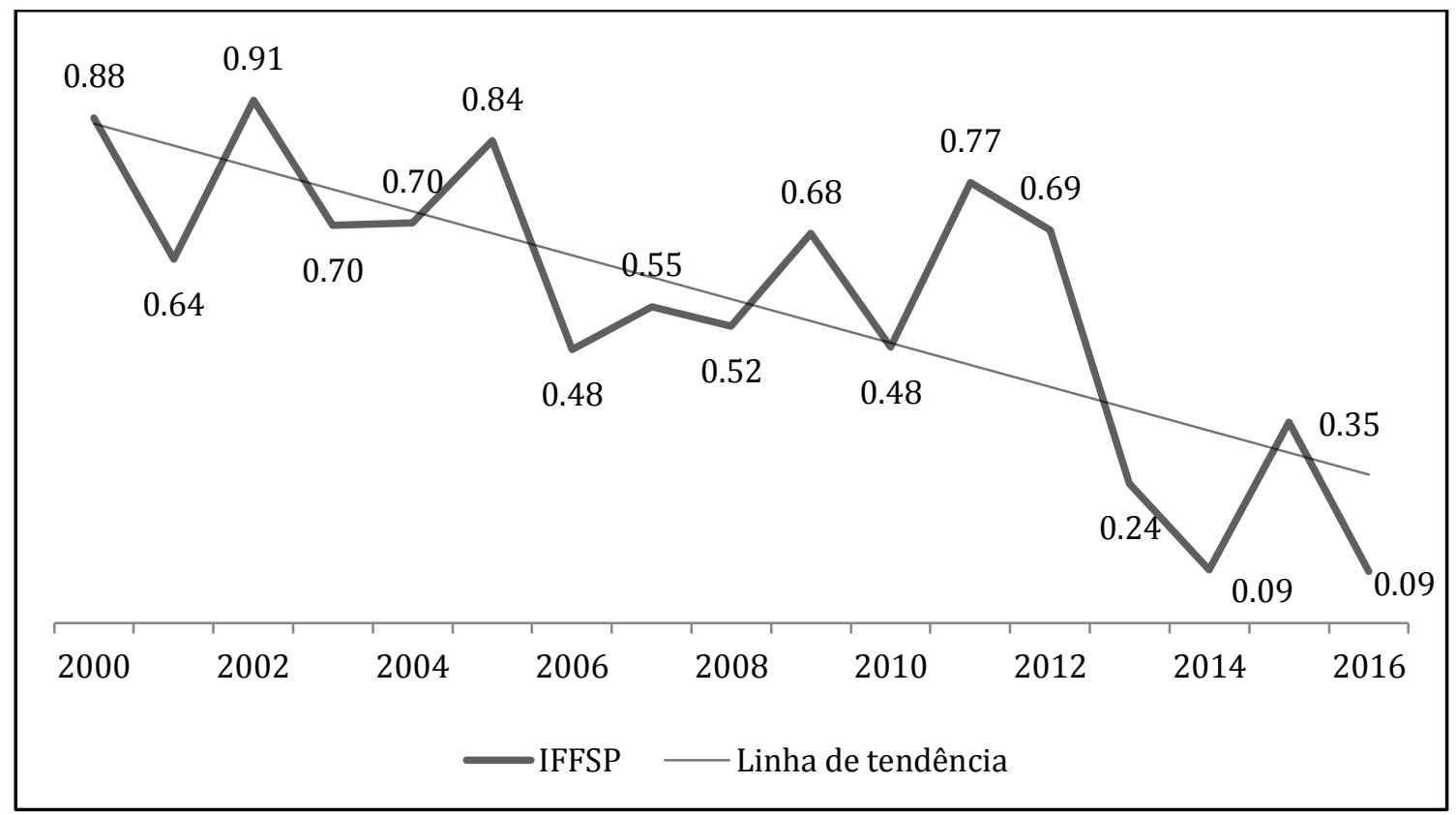

Fonte: Elaboração própria com base nos dados do Brasil (2017).

Antes de seguir com a análise do indicador cabe ressaltar o porque da retirada das operações de crédito do resultado final do indicador de fragilidade financeira do setor público. O principal motivo da sua retirada é denotado pela sua caracteristica principal, dado que como se encontra dentro do passivo circulante, é considerado como dívida nova, e dado seu valor extremamente alto, inflaria o valor da receita e superistimaria o indicador, gerando um valor 
demasiadamente viezado. A figura 2 demonstra a evolução das operações de crédito, que apesar de não compor o indicador trará resultados interessantes sobre 0 processo de endividamento público. Nota-se pela figura 2 que as operações de crédito variam na composição de $20 \%$ a $40 \%$ das receitas totais, sendo assim um componente bastante grande das receitas, gerando com sua colocação no indicador de fragilidade financeira uma posição do tipo Hedge para praticamente todos os anos, que seria um erro dado que esta variável se trata de uma dívida. Terra e Ferrari Filho (2017, p. 18, no prelo) apontam que devido aos valores positivos das operações de crédito e devido a essa alta proporção, essa rubrica evidencia que o governo brasileiro, nesse caso o setor público, detinha uma dependência alta da dívida pública para financiar seus gastos.

Figura 2 - Operações de Crédito e Receita Total (Bilhões R\$).

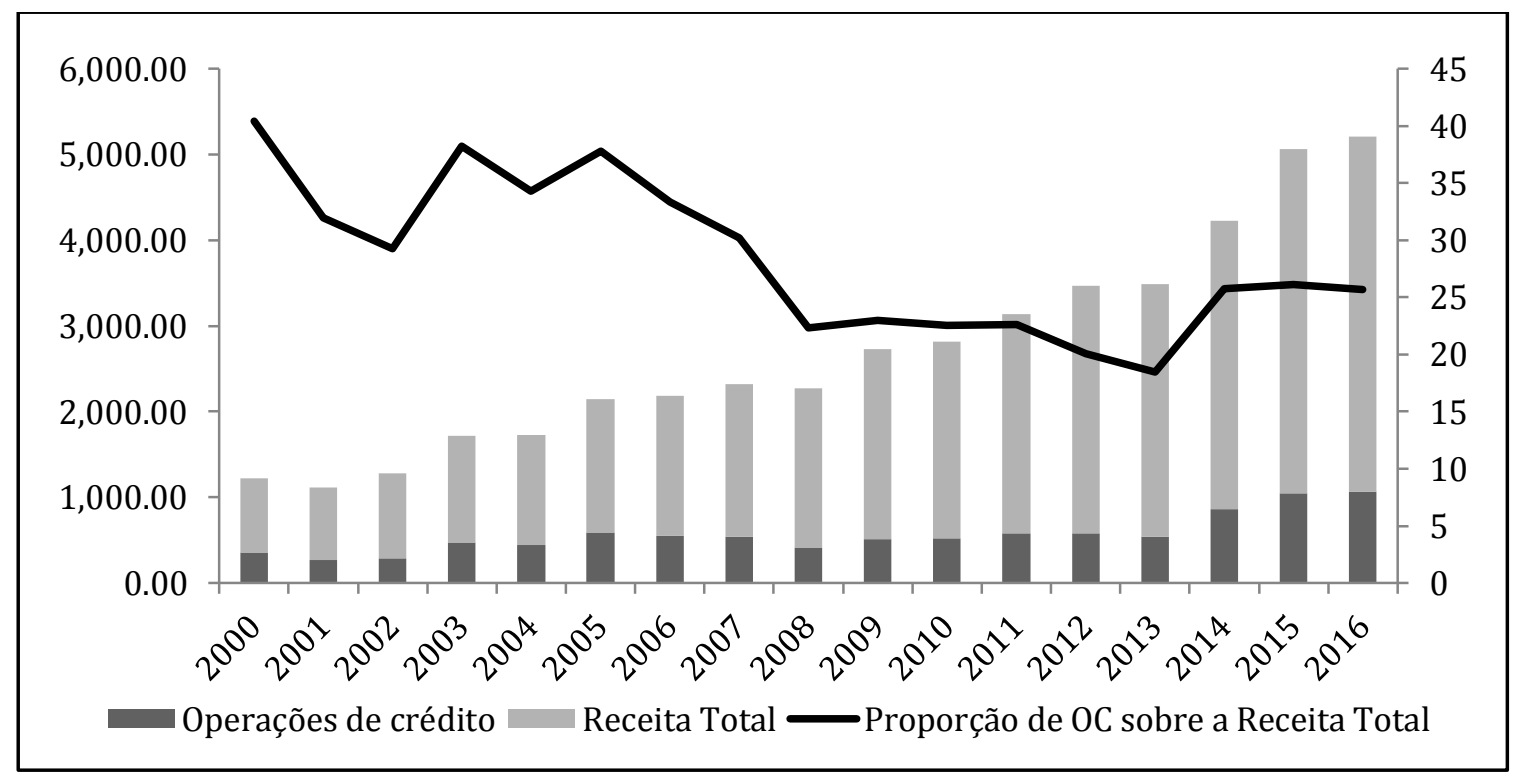

Fonte: Elaboração própria com base nos dados do Brasil (2017).

Em outro contexto vale colocar uma sucinta análise sobre o indicador de fragilidade financeira do setor público baseado no que Terra e Ferrari Filho (2017, no prelo) apresentam como requisitos de empréstimos, tentando limitar a análise para um resultado mais próximo do resultado primário do governo. Para tanto a nova equação do indicador se resume na expressão 6 :

$$
\frac{(\mathrm{T}+\mathrm{Rof})-\mathrm{G}}{\mathrm{Gi}}=1
$$

Cabe notar que os valores que o indicador deve tomar são os mesmo para a versão anterior, ou seja se for maior que 1 será Hedge, se for entre 0 e 1 será Especulativo e se for menor que 0 será Ponzi. Nota-se que a mudança para a versão anterior se encontra na exclusão das receitas de capital do cálculo, bem como os valores da amortização, basicamente mostrando a 
diferença entre as receitas e despesas não financeiras sobre os juros e encargos da dívida. De acordo com a figura 3, poder-se-á notar que até 2013 o setor público figurou-se na forma especulativa, mas chegando a ser Ponzi em 2014, voltando novamente a especulativo em 2015. É de se esperar que os valores sejam menores que o indicador anterior devido a redução das receitas, mas cabe notar que através desse indicador o setor público se mostra extremamente mais frágil, corroborando com os problemas fiscais ocorridos pós 2014. Uma ressalva apenas é que o indicador apresentado por Terra e Ferrari Filho (2017, no prelo) são para o governo central com uma base de dados diferente, o que demonstra a diferença de resultados.

Figura 3 - Índice de Fragilidade Financeira com Requisitos de Empréstimos de 2000-2015.

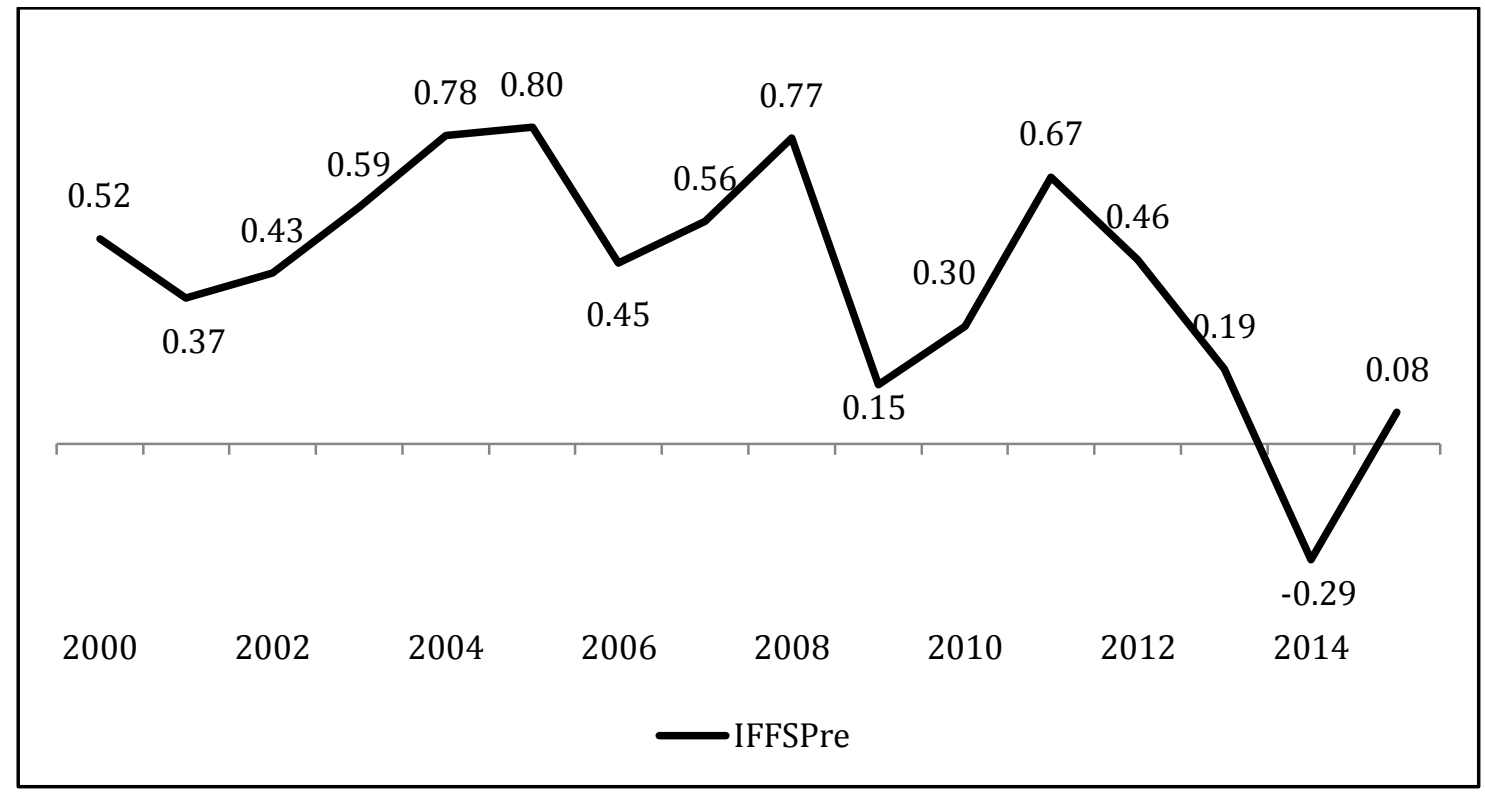

Fonte: Elaboração própria com base nos dados do Brasil (2017).

\subsection{ANÁLISE DO PROBLEMA FISCAL DO GOVERNO DILMA ROUSSEFF}

A visão Keynesiana e Pós-Keynesiana apresentada no capítulo 2, coloca que o estado tem o papel de agente estabilizador, e assim sendo precisará ter suas contas equilibradas a fim de conseguir em momentos de "crise" econômica intervir com eficiência na economia e garantir com que o fluxo de demanda continue. Nesse sentido é necessário então manter um orçamento equilibrado, a fim de manter sua credibilidade econômica e ao mesmo tempo manter um nível de dívida controlada para manter sua solvência e manter assim a capacidade de resolução de problemas.

De acordo com a figura 4, podemos acompanhar o resultado do governo central tanto para os valores nominais quantos para os valores primários, que trazem um resultado sem os impactos dos juros e encargos da dívida para o resultado orçamentário do governo central. No que tange aos valores nominais, durante toda a série ele apresenta déficit nominal, 
apresentando menor valor durante o ano de 2002, e como pior valor no ano de 2011, primeiro ano de Dilma Rousseff no poder, chegando aos $20 \%$ de déficit em proporção do PIB. Cabe notar que esse valor do déficit tem crescido nos últimos anos, principalmente pós 2014, o que pode ter sido resultado da influência da queda do PIB nesse período. Quanto ao resultado primário, o que se pode notar é que durante quase toda a série o Brasil conseguiu manter a meta pre estipulada durante o tripé macroeconômico, mas que não se sustentou após 2014, atingindo três anos consecutivos de déficit primário em proporção do PIB, muito influenciado também pela queda do produto interno bruto, mas ao mesmo tempo pelos excessivos gastos feitos durante a manuetenção da Nova Matriz Econômica, e pela política de incentivo ao investimento no governo de Dilma Rousseff.

Figura 4 - Resultado Nominal e Primário de 1997 - 2016 (\% PIB).

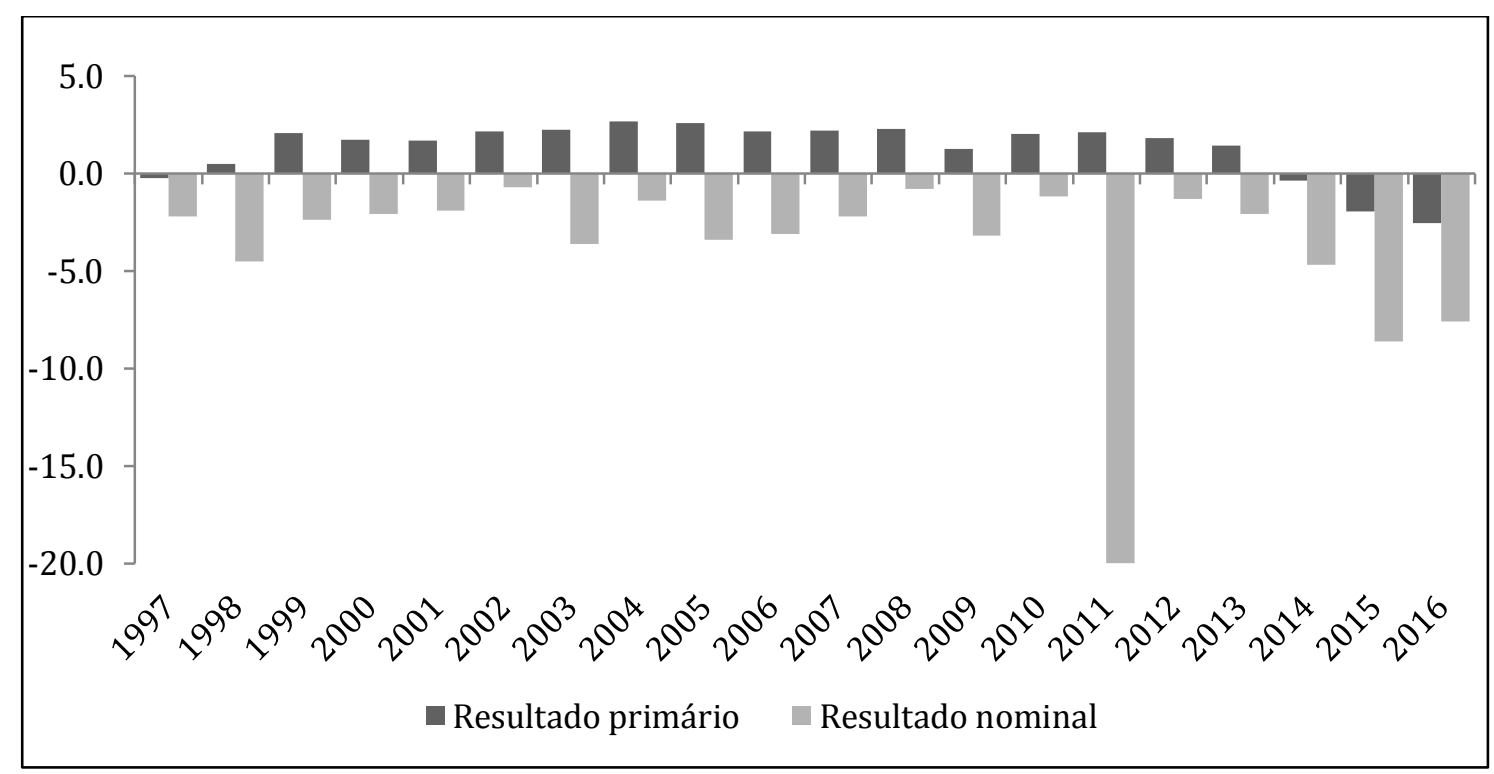

Fonte: Elaboração própria com base nos dados do STN.

A figura 5 demonstra a evolução da dívida interna bruta (DIB) e da dívida externa bruta (DEB) durante os anos de 2001 a 2016 em milhões de reais. Nota-se que a dívida interna bruta teve crescimento durante todo 0 período, com taxas altas próximas a $10 \%$ por ano, obtendo assim valores bastante altos no tocante a relação com o PIB, chegando a valores acima de $50 \%$ do PIB em todos os anos da série. Ainda sobre a DIB, cabe ressaltar que durante o governo de Dilma Rousseff seu valor quase dobrou, saindo de valores próximos de 2500000 milhões de reais em 2011, para valores próximos de 4100000 milhões em 2016. Já a dívida externa brasileira teve maior variabilidade, caindo durante todo o governo Lula, e se elevando novamente durante o governo de Dilma Rousseff, caindo no final do último ano. De acordo com os valores em proporção do PIB, cabe notar que tirando os quatro primeiros anos da série, os outros tem ficado abaixo de $10 \%$ do PIB, talvez evidenciando que realmente o maior problema seja realmente a dívida interna, o que corrobora pela reversão da dívida em 1980. Um último 
detalhe é que os valores anuais na verdade são do mês de dezembro de cada ano, bem como o ano de 2016 é do mês de agosto, mês da saída da presidente Dilma Rousseff do poder.

Figura 5 - DIB e DEB de 2001 - 2016 (Milhões R\$).

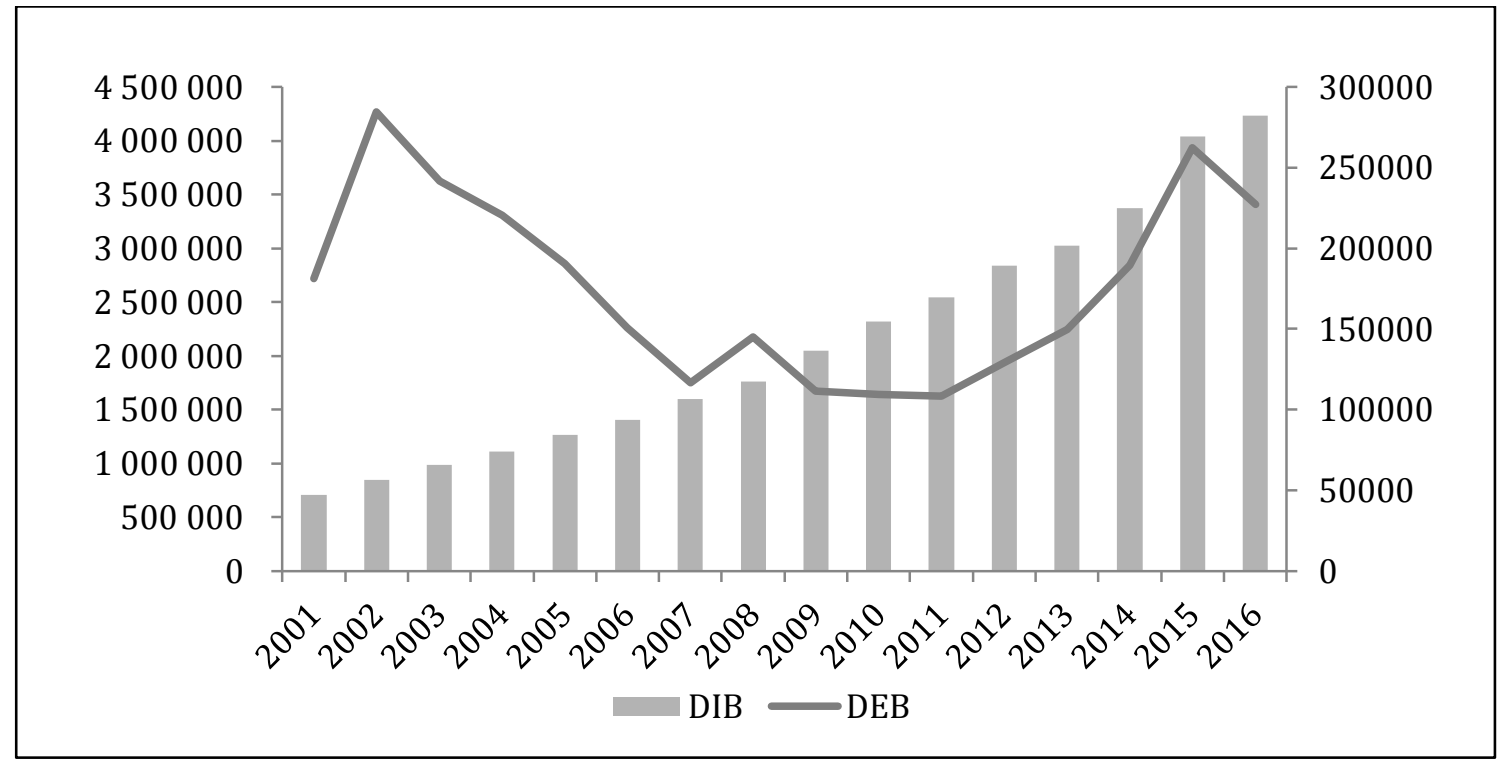

Fonte: Elaboração própria com base nos dados do BCB (2017).

No tocante mais abrangente quanto as instâncias governamentais, terse-á um indicativo da dívida líquida do governo geral (DLGG) e da dívida líquida do setor público (DLSP) de 2001 até 2016, em valores de milhões de reais. Note que a evolução das duas intâncias é bem próxima, muito devido a familiaridade entre as duas organizações, que são iguais exceto pela junção das administrações indiretas, das estaduais, muncipais e federais não financeiras por parte do setor público brasileiro (BACEN, 2008, p. 131). Numa análise mais minunciosa, cabe ressaltar que o crescimento de ambas as dívidas é padronizado e lento até 2014, levando a uma aceleração desse crescimento pós esse ano, chegando a taxas altas de crescimento entre $15 \%$ a $20 \%$. Resumidamente poder-se-á concluir que houve sim elevação aguda tanto da dívida do governo geral, quanto do setor público após 2014, com enfoque no efeito pós 2015, que é parecido com os ocorridos em 1999 com o efeito câmbio, e em 2002 com o efeito Lula, gerando repique nos valores da dívida. 
Figura 6 - DLGG e DLSP de 2001 - 2016 (Milhões R\$).

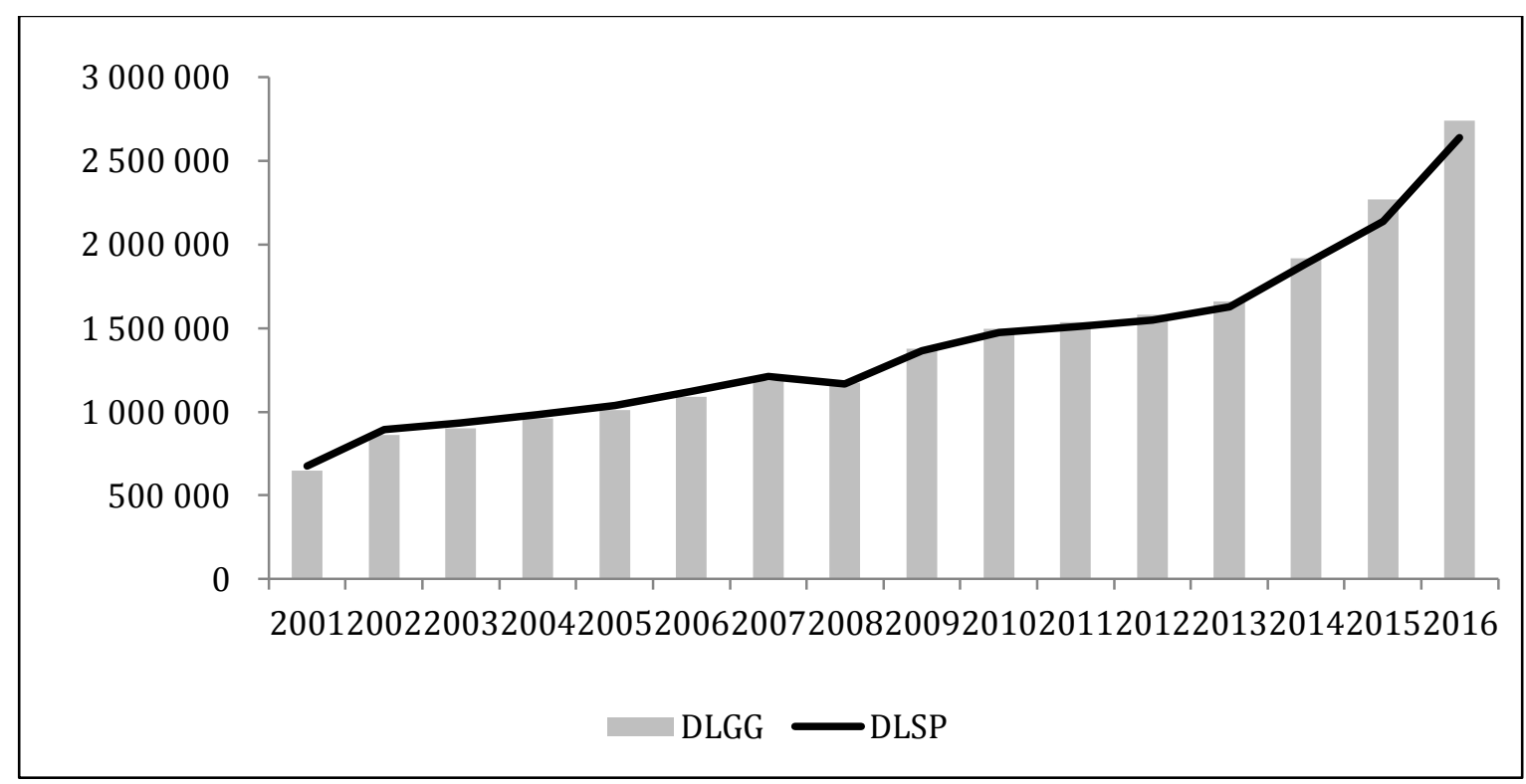

Fonte: Elaboração própria com base nos dados do BCB (2017).

A necessidade de financiamento nominal e primária é diferenciada pelos juros nominais que incidem sobre o estoque da dívida, que pode ser vista claramente na figura 7, que demonstra a evolução dessas duas variáveis em proporção do PIB, para os anos de 2001 á 2016. Como os valores nominais estão muito realcionados com o resultado nominal do governo, vale ressaltar aqui outro modo de analisar essa variável, sendo através da variação da dívida do setor público, evidenciando que até 2013 o que se nota e uma queda da NFSP nominal e real, concluindo variações menores da dívida pública, o que se reverte pós 2013 com aceleração de ambas as variáveis, que são expressivas devido a desaceleração do crescimento econômico. Cabe ressaltar que uma das principais variáveis que impacta os valores da dívida brasileira, sendo ela do setor público ou do governo geral é a taxa de juros, que pós 2013 começa a se elevar, muito devido ao repique inflacionário ocasionado pela manuetenção da Nova Matriz Econômica adotata no governo de Dilma Rousseff. Um adendo sobre a análise da dívida brasileira, é que os valores referentes aos montantes, as taxas de crescimento e as proporções sobre o PIB podem ser encontradas no apêndice. 
Figura 7 - NFSP Nominal e primário de 2001 - 2016 (\% PIB).

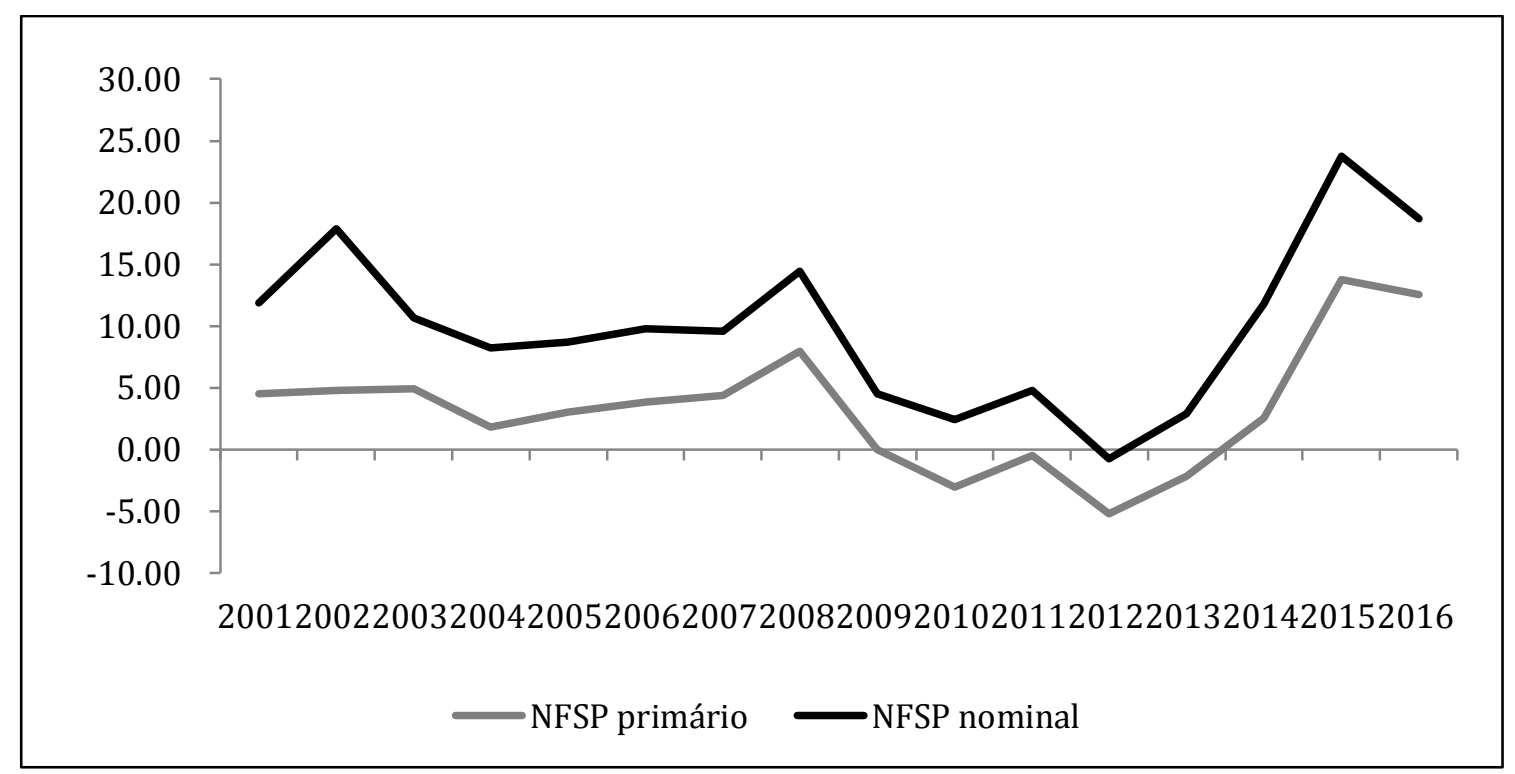

Fonte: Elaboração própria com base nos dados do BCB (2017).

As figuras dessa sessão em resumo evidenciam uma deterioração das contas públicas durante o governo de Dilma Rousseff, destacando principalmente a quebra do compromisso com o tripé macroeconomico de garantir o superávit primário com enfoque em manter o controle inflacionário, e principalmente no tocante a dívida pública que sofreu grande aceleração pós 2014, com acompanhamento da necessidade de financiamento do setor público que também apresentou valores negativos do final do governo de Dilma Rousseff até a sua saída em 2016. Cabe ressaltar que os valores da necessidade de financiamento do setor público são afetados em grande parte por seus indexadores, que pode ser exemplificado pela taxa de câmbio ou taxa de inflação, ambas se elevando pós 2013, corroborando talvez uma das justificativas dessa deterioração.

Em relação ao indicador de fragilidade financeira, nota-se que seu pior resultado foi em 2014, ano das principais reviravoltas ou acentuações dos indicadores fiscais, indicando talvez uma possível correlação entre as variáveis, mesmo que a piora dos indicadores fiscais tenha continuado pós essa data, e o de fragilidade financeira tenha conseguido se recuperar (2015), muito devido a elevação das receitas do setor público nesse período, pelo menos em valores consolidados.

Barbosa Filho (2017) evidencia que as principais causas dos problemas fiscais foram a forte intervenção do governo na economia, bem como as políticas de incentivos fracassadas, ambas bases da matriz econômica adotada no governo de Dilma Rousseff. $O$ autor ainda afirma que tais políticas não geraram só um problema fiscal, geraram queda na capacidade de crescimento da economia brasileira, afetando principalmente o lado fiscal do governo, que a princípio estava conseguindo manter pelo menos os superávits 
primários. Como solução para o problema fiscal o autor coloca que seria necessário uma consolidação fiscal, imediata ou não, para que fosse suficiente o mantimento dos superávits primário, bem como estabilização da dívida brasileira, dado que da maneira que se encontra a tendência é que ela se mantenha ligeiramente acelerada, dificultando cada vez mais qualquer ação por parte do lado fiscal de fazer politica econômica.

\section{CONSIDERAÇÕES FINAIS}

O presente trabalho buscou analisar o governo de Dilma Rousseff a luz da teoria de Hyman Minsky, buscando evidenciar o problema fiscal que se instaurou no final de seu governo, através da análise de indicadores fiscais num comparativo ao indicador de fragilidade do setor público brasileiro baseado na teoria de Minsky, utilizando a metodologia desenvolvida por Terra e Ferrari Filho (2011). Notou-se que após 2014 houve uma reversão na economia brasileira, denotada por um comportamento de aceleração inflacionária e queda do produto interno bruto, bem como por um processo de deterioração das contas públicas, acarretando em um problema fiscal, corroborado pelos indicadores fiscais apresentados.

Quanto ao indicador elaborado por Terra e Ferrari Filho (2011) mostrou que durante todo o governo de Lula e Dilma o setor público esteve em situação especulativa, com piores níveis durante o governo de Dilma, já o indicador com base nos requisitos de empréstimos evidencia uma situação ainda mais frágil do setor público, sendo especulativo na maioria dos anos, mas em 2014 chegando a ser ponzi, evidenciando e corroborando com as variáveis fiscais o problema fiscal instaurado no governo da presidenta.

Já Terra e Ferrari Filho (2017, p.21, no prelo) afirmam que os valores positivos das operações de crédito evidenciam uma necessidade do setor público em buscar refinanciamento da dívida para cobrir seus gastos, e que se não fosse os valores das receitas o indicador teria mostrado uma situação extremamente mais frágil, o que é colocado como um problema devido as receitas terem ocilação tão grande e não estarem em controle total das autoridades públicas. Os autores ainda afirmam que a situação especulativa precisa de uma elevação da margem de segurança para que conseguisse se manter, o que não foi gerado durante o governo Lula, resultando assim em queda do indicador de fragilidade financeira do setor público para as duas formas expressadas no trabalho.

\section{REFERÊNCIAS}

BARBOSA FILHO, F. de H.. A Crise Econômica de 2014 - 2017. Estudos Avançados. v. 31, n. 89, São Paulo jan./abr. 2017. Disponível em:

<http://www.scielo.br/scielo.php?script=sci_arttext\&pid=S010340142017000100051\&lng=pt\& tlng=pt> Acesso em 10 nov. 2017.

BCB. Séries Temporais de Economia e Finanças. Banco Central do Brasil. 2017.

Disponível em: < http://www.bcb.gov.br > Acesso em 16 nov. 2017. 
BRASIL. Ministério da Fazenda. Balanço do setor público nacional: exercício de 2000 á 2014. Brasília: Secretaria do Tesouro Nacional, 2017. Disponível em:

<https://www.tesouro.fazenda.gov.br/pt/balanco-do-setor-publico-nacional-bspn->.Acesso em 12 nov. 2017.

CARVALHO, F.C.. Políticas econômicas para economias monetárias. In Lima, G.T., Sicsú, J. \& Paula, L.F. de (orgs.) Macroeconomia Moderna: Keynes e a economia contemporânea. RJ: Campus, 1999, p. 258-283.

CARVALHO, F.C. Fundamentos da escola Pós-keynesiana: a teoria de uma economia monetária. In: Amadeo, E. (org.) Ensaios sobre economia moderna: teoria e história do pensamento econômico. São Paulo: Editora Marco Zero,1989, p.179-194.

DAVIDSON, P. Resgatando a revolução keynesiana. In: LIMA, G.T. \& SICSÚ, J. Macroeconomia do emprego e da renda: Keynes e o keynesianismo. Barueri, SP: Manoel, p.5-28. 2003.

ERBER, F. As convenções do Desenvolvimento no Governo Lula: um ensaio de economia política. Revista de economia política. vol.31 no.1 São Paulo Mar. 2011.

GREMAUD, A. P.; VASCONCELLOS JR., M. A. S. R. T. Economia brasileira contemporânea. Economia brasileira pós-estabilização: FHC e Lula. (cap. 18) 4. ed. São Paulo: Atlas 2002.

KINDLEBERGER, C. P.; ALIBER, R. Z.. Manias, Pânicos e Crises: A História das Catástrofes Econômicas Mundiais. 6ed. São Paulo, SP, Editora Saraiva 2013.

LOPREATO, F. L. C.. Aspectos da Atuação Estatal de FHC a Dilma. In: CALIXTRE, André Bojikian; BIANCARELLI, André Martins; CINTRA, Marcos Antonio Macedo (Ed.). Presente e Futuro do Desenvolvimento Brasileiro. Brasília: Ipea, 2014. Cap. 6. p. 227-260.

MINSKY, H. P.. Estabilizando uma economia instável. São Paulo: Novo Século. 2013.

POSSAS, M.L.. Demanda Efetiva, investimento e dinâmica: Atualidade de Kalecki para a teoria macroeconômica. Revista de Economia Contemporânea. 3(2); p. 17-46, jul-dez 1999.

SINGER, A. Cutucando onças com varas curtas: o ensaio desenvolvimentista no primeiro mandato de Dilma Rousseff (2011-2014). Novos Estudos Cebrap, v.1, n.102, p. 39-67, 2015. Disponível em:

<http://novosestudos.uol.com.br/v1/files/uploads/contents/content_1604/file_1604.pdf>. Acesso em 16 maio 2017.

SINGER, A. Realinhamento, Ciclo Longo e Coalizões de Classe. Revista de Economia PUC-SP, ano 2, n. 4, jul./dez. 2010.

STN. Estatísticas Fiscais. Secretária do Tesouro Nacional. 2017. Disponível em : <http://www.tesouro.fazenda.gov.br> Acesso em 15 de ago. 2017.

TERRA, F. H. B.; FERRARI FILHO, F.. A hipótese da fragilidade financeira aplicada ao Setor Público: uma análise para a economia brasileira no período de 2000 a 2009. Brasília (DF), v.12, n.3, p.497-516, set/dez 2011. Disponível em:

<http://www.anpec.org.br/revista/vol12/vol12n3p497_516.pdf>. Acesso em: 22 out. 2017. 
TERRA, F.H.B.; FERRARI FILHO, F.. Public Sector Financial Fragility Index revisited: the Brazilian federal government from 2000 to 2016. In: X encontro Internacional da Associação Keynesiana Brasileira, Brasília, 2017. No Prelo. 